\title{
REDES SOCIAIS COMO LUGARES ENVIESADOS DE MEMÓRIA: UM DISCURSO COLETIVO DA PARALISAÇÃO DOS CAMINHONEIROS DE 2018
}

\author{
SOCIAL NETWORKS AS BIASED PLACES OF \\ MEMORY: THE DISCOURSE OF THE COLLECTIVE \\ SUBJECT ABOUT STRIKE BY TRUCK DRIVERS IN \\ BRAZIL
}

\author{
Denise Braga Sampaioa \\ Izabel França de Limab \\ Maria Nilza Barbosa Rosac \\ Bernardina Maria Juvenal Freire de Oliveirad
}

\section{RESUMO}

Trata-se de pesquisa exploratória cujo objetivo principal é o de descortinar as relações existentes entre memória coletiva e redes sociais, em especial, o Instagram. Os objetivos específicos são verificar as fotografias relacionadas à paralisação dos caminhoneiros (ocorrida em maio 2018) no Instagram do jornal cearense O Povo Online, categorizar essas publicações segundo critérios de forma e conteúdo e verificar as ideias principais enunciadas nas legendas das fotografias das postagens mais curtidas pelos leitores. Para tal apreciação, toma por instrumentos da pesquisa o questionário semiestruturado e as matérias do $O$ Povo Online referentes à paralisação. Os dados levantados no questionário foram sopesados pelo Discurso do Sujeito Coletivo e comparados com as publicações do jornal, tendo por resultado que as redes sociais são uma potencial ferramenta de rememoração, no entanto, limitadas graças à sua natureza dinâmica e fluida.

a Doutoranda do Programa de Pós-graduação em Ciência da Informação da Universidade Federal da Paraíba (UFPB). Professora do Departamento de Documentação e Informação do Instituto de Ciência da Informação da Universidade Federal da Bahia (UFBA). E-mail: denise.sampaio@ufba.br.

b Professora do Departamento e do Programa de Ciência da Informação da Universidade Federal da Paraíba (UFPB). E-mail: belbib@gmail.com.

c Doutora em Letras pela Universidade Federal da Paraíba (UFPB). Pesquisadora do Programa de Pós-Graduação em Ciência da Informação da Universidade Federal da Paraíba (UFPB). Email: nilzasor@yahoo.com.br

d Doutora em Letras pela Universidade Federal da Paraíba (UFPB). Professora Adjunta do Departamento de Ciência da Informação, PPGCI e PPGOA da Universidade Federal da Paraíba (UFPB). E-mail: bernardinafreire@gmail.com 
Descritores: Memória Coletiva. Redes Sociais. Greve. Transporte Rodoviário.

\section{INTRODUÇÃO}

A sociedade é composta das interações humanas consigo, com a natureza e com a narrativa dessas interações, que passou pela oralidade e se inscreveu numa cultura escrita, para maior alcance e validade. Nesse sentido, os conhecimentos são passados de geração em geração, por meio destes mecanismos de disseminação, de fala e escrita, propiciados pelo registro dos fatos históricos e cotidianos. Ao se partir da perspectiva de que o conhecimento é gerado, registrado e transmitido, é possível afirmar que a memória o perpassa e é construída das interações e das vivências subjetivas, que se interconectam e interinfluenciam.

Com a ascensão das Tecnologias da Informação e da Comunicação (TIC) e a neofilia que as acompanhou, as relações estabelecidas entre a memória, fato e percepção passaram por uma nova forma de se constituir. As vicissitudes dos jogos informativos e a necessidade de estar sempre informado, em uma sociedade dita "da informação", tornou os indivíduos consumidores acríticos e replicadores de narrativas de vozes sem rosto. Correntes nas redes sociais, vídeos de pessoas leigas em plataformas como o YouTube passaram a constituir fontes de informação aceitáveis pela fácil absolvição, ocasionada pela linguagem acessível, pelo apelo imagético e pela rapidez de transmissão (GASQUE, 2016; FERREIRA; LUZ; MACIEL, 2015), além disso, como evidencia Gasque (2016), esse uso das mídias faz com que os sujeitos estejam imersos em bolhas de preferências pautadas por algoritmos, o que limita a capacidade de seleção/escolha. Nesse sentido, os fatos são narrados a partir da percepção resultante da inserção nessas bolhas informacionais e não na averiguação, comparação e criticidade que permitem uma apreciação, o mais próximo possível, da verdade fatual.

O cenário da Crise dos combustíveis de 2018, ou Crise do Diesel (MOURA, 2018), pode ser descortinado como exemplo dessa nova forma de lidar com as informações e os fatos que as originam. As interações entre verdade, 
opinião e público são costuradas nas narrativas jornalísticas, nos relatos dos caminhoneiros, por vezes, mediados por em suas redes sociais, mas também no discurso e análise dos que não pertencem à mídia, nem à classe que deflagrou a paralisação. São discursos de pessoas comuns, especialistas ou não, investigadoras ou não, que decidem expor sua percepção, neste mesmo ambiente, a respeito do fato em curso e das implicâncias deste em suas vidas. As redes sociais, invariavelmente, tornam-se fontes de consulta e exposição de pareceres, informações são consumidas e opiniões emitidas nestes ambientes, como um ciclo retroalimentado. Um desses meios, o Instagram, como versa seu criador, Mike Krieger, tem por intuito principal "resgatar a nostalgia do instantâneo, cunhada ao longo de vários anos pelas clássicas Polaroides" (PIZA, 2012, p. 7). Tal plataforma se torna uma ode à instantaneidade e à imagem, que tanto pode ser estática, como em movimento. Seus usuários interagem por meio dessas imagens, que são complementadas por textos curtos e médios, como forma de transmitir seus pensamentos.

Questiona-se, portanto: como a narrativa que envolveu a paralisação dos caminhoneiros, realizada em maio de 2018, fora gestada no Instagram e como pode influenciar a geração de uma memória coletiva dentro da plataforma? Tais questões traduzem-se nos seguintes objetivos: analisar as publicações da página do jornal O Povo no Instagram; verificar as fotografias relacionadas à paralisação no Instagram do referido jornal; categorizar essas publicações segundo critérios de forma e conteúdo; e verificar as ideias principais enunciadas nas legendas das fotografias das postagens mais curtidas pelos leitores. Paralelo a isso, os resultados dos questionários constituem o Discurso do Sujeito Coletivo que é comparado com as postagens selecionadas no Instagram do Jornal O Povo.

\section{PERCURSO METODOLÓGICO}

Buscando maior familiaridade com o tema, da relação entre memória coletiva e as redes sociais, tal estudo, quanti-qualitativo, descortina as interações na referida rede, tomando por assunto a paralisação dos caminhoneiros, ocorrida 
em 2018, e como esta fora tratada pelos usuários do Instagram. Para que seja possível tal apreciação, utiliza-se da análise do discurso do sujeito coletivo, de Lefevre, Lefevre (2014, p. 503) que consiste, basicamente, em

[...] uma forma de metodologicamente resgatar e apresentar as RSs obtidas de pesquisas empíricas. Nessas, as opiniões ou expressões individuais que apresentam sentidos semelhantes são agrupadas em categorias semânticas gerais, como normalmente se faz quando se trata de perguntas ou questões abertas. O diferencial da metodologia do DSC é que a cada categoria estão associados os conteúdos das opiniões de sentido semelhante presentes em diferentes depoimentos, de modo a formar com tais conteúdos um depoimento síntese, redigido na primeira pessoa do singular, como se tratasse de uma coletividade falando na pessoa de um indivíduo.

O Discurso do Sujeito Coletivo (DSC) apresenta quatro operadores: as expressões-chave $(E C H)$, que "[...] são pedaços, trechos do discurso, que devem ser destacados pelo pesquisador, e que revelam a essência do conteúdo do discurso ou a teoria subjacente"; as ideias centrais (IC), a ancoragem (AC), que não foi trabalhada nesta análise e o DSC, que "[...] é uma reunião num só discurso-síntese homogêneo redigido na primeira pessoa do singular de $\mathrm{ECH}$ que têm a mesma IC ou AC." (Lefevre; Lefevre, 2003, não paginado).

Para fins de realização deste artigo, a coleta de dados se dá, inicialmente, a partir do levantamento de fotos e de legendas relativas à paralisação dos caminhoneiros na página jornalística $O$ Povo Online, no Instagram, um dos maiores jornais (há sua versão impressa também) eletrônicos do Estado do Ceará. As etapas seguintes correspondem à montagem do DSC, com a coleta das ideias centrais e composição do discurso. Para tal, realizou-se um questionário semiestruturado aplicado no Instagram e no WhatsApp, entre os dias 18 e 19 de julho, totalizando treze respondentes. As perguntas, seis ao todo, referiram-se à percepção dos participantes em relação à paralisação, bem como o local em que viviam. A etapa de ancoragem não ocorreu, uma vez que "marcas discursivas explícitas" não foram encontradas. Ao final do DSC, comparou-se as matérias em alta do O Povo Online, em sua página no Instagram, com as respostas dos participantes ao questionário. 


\subsection{A Paralisação dos Caminhoneiros como Fato Apreciável}

O direito à greve é garantido pela constituição desde 1989, resguardo pela Lei 7.783, cuja natureza expressa "[...] sobre o exercício do direito de greve, define as atividades essenciais, regula 0 atendimento das necessidades inadiáveis da comunidade, e dá outras providências" (BRASIL, 1989, não paginado). Em outras palavras, trabalhadores cuja atividade não represente riscos à segurança nacional, ou à saúde pública, são portadores do direito de greve, ou seja, aqueles que não lesem o direito a serviços ou atividades essenciais. Como mostra o art. 11, 12 e 13 (BRASIL, 1989, não paginado, grifo nosso)

Art. 11. Nos serviços ou atividades essenciais, os sindicatos, os empregadores e os trabalhadores ficam obrigados, de comum acordo, a garantir, durante a greve, a prestação dos serviços indispensáveis ao atendimento das necessidades inadiáveis da comunidade.

Parágrafo único. São necessidades inadiáveis, da comunidade aquelas que, não atendidas, coloquem em perigo iminente a sobrevivência, a saúde ou a segurança da população.

Art. 12. No caso de inobservância do disposto no artigo anterior, - Poder Público assegurará a prestação dos serviços indispensáveis.

Art. $13 \mathrm{Na}$ greve, em serviços ou atividades essenciais, ficam as entidades sindicais ou os trabalhadores, conforme o caso, obrigados a comunicar a decisão aos empregadores e aos usuários com antecedência mínima de 72 (setenta e duas) horas da paralisação.

Ainda sobre a Lei 7.783/1989, o Art. 17 determina que "fica vedada a paralisação das atividades, por iniciativa do empregador, com o objetivo de frustrar negociação ou dificultar o atendimento de reivindicações dos respectivos empregados (lockout)" ou locaute. O direito à greve, portanto, é orgânico e estritamente ligado à classe trabalhadora, que tanto pode se organizar de forma sindicalizada, como por meio de coletivos, mas, de forma alguma, por intermédio do patronado.

Segundo Portinari (2018), a greve dos caminhoneiros (tratada, pelas pesquisadoras como paralisação, para eximir possíveis juízos de valor), teve por ponto de partida o aumento do preço dos combustíveis, em especial, o diesel. 
Este aumento fez com que os caminhoneiros também modificassem o valor de seus serviços, repassando-os ao consumidor final, o que gerou um efeito em cadeia. Borges (2018, não paginado) mostra que "a política da Petrobras de acompanhar a oscilação internacional dos preços do petróleo levou a um aumento acumulado de $55 \%$ no valor dos combustíveis no Brasil ao seguir a variação internacional do preço do petróleo". O motivo dessa política de acompanhamento do dólar (iniciada em julho de 2017) foi uma tentativa do Governo Federal (GF) reaquecer o setor de combustíveis, em desfavor da política subsidiária do anterior (Governo Dilma Rousseff), de retenção do preço do combustível, para que não chegasse ao consumidor final, com valores elevados. Tal política subsidiária, nas palavras de Moura (2018), onerou a petrolífera brasileira, "agindo assim, o governo evitava que a elevação do preço dos combustíveis se disseminasse pela economia afetando os outros produtos que dependem diretamente de transporte rodoviário e de insumos derivados do petróleo, capitalizando o impacto na inflação geral" (MOURA, 2018, não paginado). Em teoria, isso fez Pedro Parente, então presidente da Petrobrás, adotar medidas antipopulares de aumento quase diário do diesel, da gasolina, do gás e do etanol.

Entre as pautas iniciais da paralisação estavam a diminuição do preço do óleo diesel (principal combustível usado pela classe), corte de impostos (PIS/Cofins) e a revisão da política de preços da Petrobras, que faz o valor flutuar junto com a variação do dólar. Ao longo da paralisação, outras pautas foram acrescidas, como o pedido de suspensão do pagamento de pedágio para caminhões que trafegassem vazios nas rodovias, e a aprovação do Projeto de Lei n. 528/2015, "que cria uma política de preços mínimos para o frete e o marco regulatório para caminhoneiros. Isso evitaria a frequente situação que os caminhoneiros passam, quando fazem a estimativa do frete e, durante o trajeto, o preço do combustível aumenta, invalidando os cálculos prévios" (MOTTA, 2018, não paginado) e, já no processo de desmobilização, caminhoneiros autônomos pediram intervenção militar (MANOLO, 2018). Essas pautas fizeram gerar dúvidas em relação à legitimidade e organicidade do movimento, dividindo 
analistas e opinião pública no entendimento deste como sendo uma greve do setor, ou como sendo um locaute, dado que determinadas pautas que interferem diretamente no trabalho dos caminhoneiros não foram reivindicadas, como condições de trabalho, cumprimento do banco de horas, segundo a Consolidação das Leis do Trabalho (CLT) e as Leis do Caminhoneiro (Lei n. 12.619/2012) e do Descanso (Lei n. 13.103/2015).

Manolo (2018, não paginado) destaca números levantados pelo estudioso Ruy Braga, que frisa:

[...] há no Brasil 2 milhões e 300 mil caminhoneiros, dos quais $70 \%$ são 'autônomos'; agrupando-se aí desde os donos de um único caminhão a donos de dois ou três veículos que revezam seu uso com 'agregados', ou seja, trabalhadores precarizados também incluídos entre os 'autônomos'/ 'por conta própria' em formas bastante precarizadas de submissão aos donos dos veículos. Há também outros $30 \%$ de 'empregados', ou seja, de 'celetistas' com vínculo formal, mas sujeitos a formas sofisticadas de precarização, como cooperativas e terceirização.

Ou seja, independente do vínculo, ou não, com algum patrão, os caminhoneiros passam por uma situação de trabalho muito aquém do ideal, o que justifica e legitima o ato. Não há, no entanto, um consenso a respeito da Paralisação dos Caminhoneiros, de 2018, configurar-se em greve ou em locaute. Ruy Braga, por exemplo, acredita que não se trata de um locaute, com base no levantamento que expos acima, já Marília Moschkovich (GREVE DE..., 2018) acredita que sim, elencando dezessete indícios que justificam seu entendimento, que vai desde denúncias de corrupção ao líder do Movimento União Brasil Caminhoneiros (MUBC), Nélio Botelho, ocorridas em 2013, até o questionamento a respeito da pauta sobre a diminuição do valor dos impostos e do preço do diesel, ao invés do pedido de aumento proporcional do valor do frete. Outro ponto que a autora destaca é a falta de pautas referentes às condições de trabalho dos caminhoneiros que responsabilizassem as empresas contratantes. Já Ricardo Antunes, crê que a paralisação é "uma mistura de greve com locaute" (MOTA, 2018, não paginado). O pesquisador afirma:

Eu vejo um pouco dos dois. Como é uma greve que em poucos dias se tornou expressiva, e as empresas têm algo como 55\% do controle desse transporte (frete rodoviário), muitas dessas paralisações podem ser decisão empresarial. O restante, os 
$45 \%$ de caminhoneiros autônomos, são muito afetados pelo contexto de recessão, que diminui a circulação de mercadorias. Eles já estavam ganhando muito pouco, e o preço do combustível explodiu. Acredito que há uma espécie de confluência nesse momento entre os interesses de empresas e caminhoneiros. (MOTA, 2018, não paginado)

O cenário descortinado à época, portanto, era de incertezas, o que tornou o ambiente propício a várias interpretações. Esse jogo de interpretações permeou as narrativas das redes sociais nos onze dias de greve. Vale destacar que a própria articulação dos grevistas ocorreu nesses ambientes, especialmente no Facebook e no WhatsApp (MOTA, 2018). Outras redes, como o Twitter, tiveram o assunto como Trending Topic ${ }^{1}$, ficando em segundo lugar no Twitter Brasil (“GREVE..., 2018) e, no Instagram, as hashtags principais sobre o assunto foram: \#grevedoscaminhoneiros, \#caminhoneiro e \#caminhoneiros, gerando 104.389 menções apenas com essas etiquetas, em maio de 2018. Ao todo, as redes sociais totalizaram aproximadamente 8,8 milhões de menções à paralisação, segundo dados do Departamento de Análise de Políticas Públicas (DAPP), da Fundação Getúlio Vargas (FGV) (GRAVE DOS..., 2018), no transcorrer da paralisação. Os números denotam o poder de agregação e troca de ideias destas plataformas, a respeito do assunto.

\subsection{O Instagram COMO Plataforma de Trocas Informacionais}

O Instagram é uma rede social disponível para os maiores sistemas operacionais de celular (Android, IOS e Windows Phone), cuja atual função é o compartilhamento de fotos. No entanto, o Instagram não nascera com este intuito, como mostra a cronologia feita a partir dos dados do portal de notícias G1 (ENTENDA..., 2012):

\footnotetext{
${ }^{1}$ Lista de palavras, em tempo real, formada a partir dos termos mais citados na plataforma.
} 
Figura 1 - Origem e cronologia do Instagram

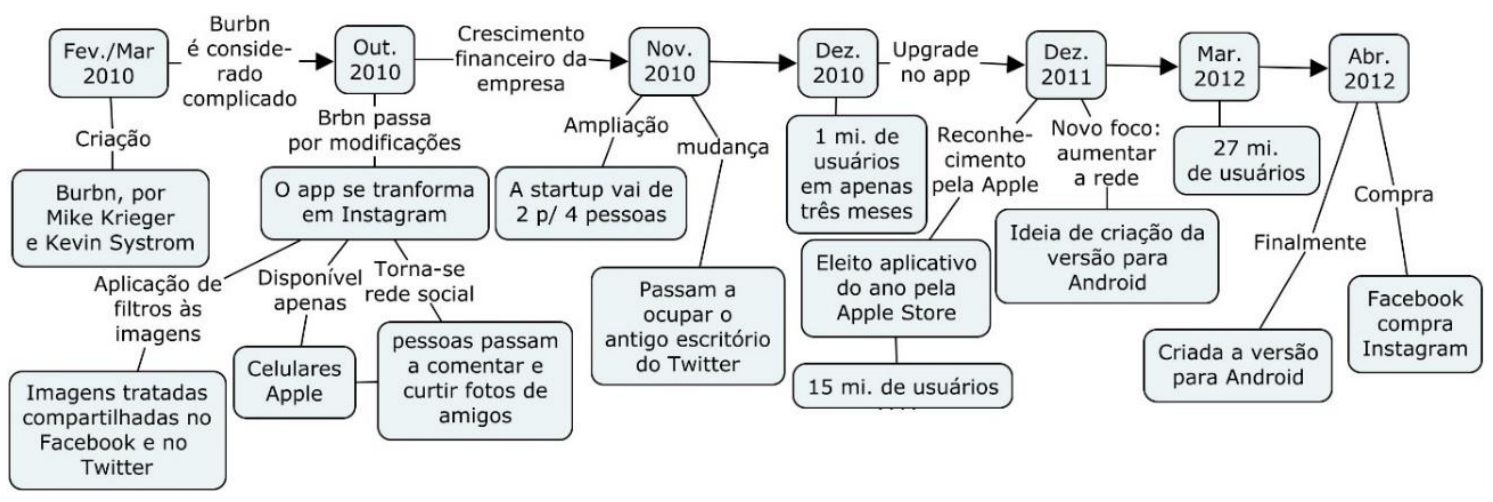

Fonte: Elaborado pelas autoras, baseada em Entenda... (2012)

O Instagram era, em seu início (Figura 1), uma ferramenta de manipulação de imagens que servia de suporte a outros aplicativos. Com as mudanças ocorridas de 2010 para 2011, este passou a oferecer fotos de maior qualidade e as interações tornaram-se muito maiores, com o aumento do número de adeptos. A compra do Instagram, em 2012, por Mark Zuckerberg (CEO e criador do Facebook) e a adesão do aplicativo ao catálogo da Google Store foram marcos importantes para sua expansão. Outros recursos surgiram ao longo destes oito anos, como a criação dos Stories (recurso de mensagens visuais de curto período de duração), as transmissões ao vivo e, mais recentemente, a criação do IgTV, aplicativo de vídeos longos da plataforma. Além destes recursos, o Instagram conta com as hashtags, que são etiquetas criadas pelos usuários para categorizar seus conteúdos, de forma a facilitar o alcance destas postagens a um número maior de pessoas. Pensando nisso, o próprio Instagram, em 2017, habilitou a possibilidade de seguir determinadas hashtags, ou seja, aparecem, no feed do usuário, postagens relacionadas àquela etiqueta que se resolveu 'seguir'.

O crescimento do Instagram, assim como de outras redes sociais, o tornou plataforma de compartilhamento de notícias. Muitos jornais criaram perfis neste ambiente para ter maior contato com seus consumidores, publicando informações multimídia amparadas por textos redigidos nas legendas.

[...] o uso de redes sociais digitais, como Facebook e Instagram, por sítios jornalísticos, cresce devido às possibilidades de inserção de conteúdos multimidiáticos em seus perfis, que 
podem ser consumidos por diferentes dispositivos tecnológicos e possuem características de interação. O/A internauta consegue complementar a informação pelos comentários, mensagens diretas, além de compartilhar os conteúdos em seus perfis pessoais. (LUZ; WOITOWICZ, 2017, p. 4)

Essa interação dos jornalistas por meio deste tipo de plataforma reforça a relação atual da sociedade com a fotografia. Revelar, ocultar, lembrar e esquecer são ações muito mais fluidas nesse ambiente. A fotografia ganhara um novo status, que transpassa a memória de que falara Le Goff (1990), dado que o ato de tirar fotos sai do plano de mero registro para promover a espetacularização de pessoas e momentos, tornando-os públicos na sua concepção mais ampla e extraterritorial. A apreciação dos álbuns de fotografia, retratados pelo autor (LE GOFF, 1990), torna-se agora uma contemplação do imediato.

Produzimos tanto quanto consumimos: somos tanto homo photographicus quanto simples viciados em fotos (quanto mais fotos melhor), nada sacia nossa sede de imagens, um sintoma da pós-modernidade (FONTCUBERTA, 2012, p. 31).

Também efeito dessa pós-modernidade, ou da espetacularização das relações, as imagens são produzidas com o intuito de gerar resposta imediata dos que a veem, são termômetro sociais. Portanto, quão mais enxutas e quão significativas em si, melhor. Certamente por isso, o Instagram tem crescido tão rápido, em tão pouco tempo, por possibilitar que esses homo photographicus deem vazão às suas criações e recriações de si. Nesse sentido, a narrativa dos fatos, no Instagram, é mais limitada, dado que os conteúdos devem ser sucintos e envoltos em estímulos visuais diversos. Isso gera menor aprofundamento das discussões, potencializado pela limitação das legendas e pela limitação do espaço de comentários. A alternativa que as páginas jornalísticas adotam é a vinculação do link para o jornal em seu perfil. Além disso, a própria possibilidade de comentar as notícias é dificultada pela falta de aprofundamento causada pelo imediatismo das notícias e pouco conhecimento dos internautas, que mergulham no campo das opiniões. Diante dessas barreiras dialógicas, como fica a construção de uma memória coletiva em um ambiente tão fluido? 


\section{MEMÓRIA COLETIVA E SUA CONSTRUÇÃO EM MEIO À LIQUIDEZ}

Segundo Bosi (1995), estamos inscritos no tempo, existimos nele e essa existência é determinada pela passagem e não pela permanência. Nós vivemos no tempo e não o tempo em nós. Por isso, criamos mecanismos que nos fazem tentar poupar ou estender o tempo, em uma leda ilusão. Dessa tentativa, surge, por exemplo, a mais-valia relativa percebida por Marx (1867), dado que as tecnologias são inseridas no trabalho para aumento de produção, mas o tempo despendido pelo trabalhador não é alterado, tampouco, este é beneficiário desta produção otimizada. Essa máxima pode ser percebida em outros espaços, no nosso cotidiano, nas ações sociais que nos enredam. Bosi (1995, p. 2), a esse respeito, afirma que:

A tecnologia, tal como se constituiu no âmbito da sociedade industrial, é diametralmente oposta à ascese e à pura contemplação: o seu projeto é multiplicar imagens, multiplicar palavras, multiplicar elementos de informação e multiplicar instrumentos práticos cujo desígnio é abreviar o tempo e poupar esforço, quer o esforço muscular, quer um certo tipo de esforço mental, como, por exemplo, o da memória.

Não é à toa que, cada vez mais, recorremos aos smartphones e outros gadgets, para lembrarmo-nos de reuniões, eventos, aniversários. As tecnologias, em certa medida, tornam-se próteses dos sentidos. A construção da memória, assim, perpassa, muitas vezes, pelas ferramentas tecnológicas, principalmente quando na coletividade. As narrativas construídas no plural são registradas por meio destas ferramentas, desde os primeiros suportes de registro que a humanidade conseguiu manipular e criar (a caverna e a tinta, a argila, o papiro etc.). Essa necessidade de registrar vem de um ímpeto comunicacional humano, uma necessidade de transitar informações, conhecer, aprender e ensinar.

[...] é possível dizer que os próprios meios eletrônicos de comunicação, nas suas múltiplas formas de multimeios, proporcionam momentos de satisfação de nossas curiosidades; e, em um nível humano superior, propiciam momentos de interlocução com o semelhante, os sempre almejados momentos de comunicação, efeito nada desprezível, considerando quanto é grande a solidão do homem em uma sociedade de massa (BOSI, 1995, p. 5).

A informação, por seu turno, serve como matéria prima à comunicação e 
à própria memória, sendo constituinte de ambas. Como afirma Janet (LE GOFF, 1990, p. 425), "[...] o ato mnemônico fundamental é o 'comportamento narrativo' que se caracteriza por sua função social, pois que é comunicação a outrem de uma informação [...]", essa informação é a representação de um fato ou acontecimento. Halbwachs (1990) assevera que, para acessarmos nosso passado, nos valemos das lembranças de outras pessoas, funcionando estas como "referências que existem fora de si". Valemo-nos delas, dentro de um universo simbólico socialmente inteligível para compor nossas narrativas e evocar nossas lembranças. Tais lembranças são constituintes do sujeito, "[...] não conseguimos lembrar senão do que vimos, fizemos, sentimos, pensamos num momento do tempo, ou seja, nossa memória não se confunde com a dos outros" (HALBWACHS, 1990, p. 72). Esse acesso às nossas lembranças constitui a memória individual, esta é única, mas não isolada ou fechada, isso se dá por este acesso de que fala Halbwachs (1990), mas também pela possibilidade de contato com as memórias coletivas, uma se constitui a partir da outra e também de uma terceira, a memória histórica, esta última, contém a narrativa oficial do fato, construída nas relações de poder que se estabelecem na disputa por essa narrativa oficial (LE GOFF, 1990; KESSEL, 2003).

[...] a memória coletiva é não somente uma conquista, é também um instrumento e um objeto de poder. São as sociedades cuja memória social é sobretudo oral ou que estão em vias de constituir uma memória coletiva escrita que melhor permitem compreender esta luta pela dominação da recordação e da tradição, esta manifestação da memória (LE GOFF, 1990, p. 477)

As disputas de que falam os autores envolvem verdades socialmente aceitas, tomadas por universais, a partir de entendimentos agradáveis à maioria e possíveis a partir das negociações e tensões com os detentores do poder, validadores de uma memória histórica, ou oficial (BELO, 1994). Os jogos de poder são facilmente possíveis nas sociedades pré-modernas. Como afirma Hannah Arendt (2016), neste período, as autoridades tinham forte influência sobre a população, sejam autoridades papais, filosóficas, ou científicas, sendo detentoras e disseminadoras da verdade, por meio da evidenciação empírica ou do dogmatismo. 
Hodiernamente, o avanço das tecnologias e a possibilidade de saída de uma narrativa uníssona, para uma cultura oral/escrita polifônica faz estremecer o poder destas autoridades. Um dos grandes marcos, a prensa de Gutemberg, deu liberdade para a expansão livresca, o que impulsionou a burguesia a produzir suas próprias narrativas e, consequentemente, visões de mundo, apesar disso, o acesso a esses materiais era, ainda, elitizado (HOBSBAWN, 1977). Somente com o avanço das Tecnologias da Informação e da Comunicação (TIC) e com a criação da internet, sobretudo em sua fase 2.0, as mudanças passam a ser mais consubstanciais, no entanto, como assevera Demo (2000, p. 40), “[...] a sociedade continua bastante 'desinformada', seja porque the chega tendencialmente informação residual, ou porque se lhe impõe informação oficial, ou porque se entope atabalhoadamente [...]". Soma-se a isso a liquidez das reações e o caráter individualista que permeia a sociedade atual (BAUMAN, 2011). No contexto da sociedade líquida, tudo é passível de tornarse mercadoria, inclusive as relações. Os contatos sociais são pontuais e unilaterais, pouco se escuta, mas muito se fala. Retrato disso, as redes sociais tornaram-se verdadeiros megafones para públicos surdos. Este comportamento ocorre dadas as dificuldades de aprofundamento e conhecimento em relação aos temas debatidos na rede. Esse movimento advém de uma espécie de neofilia porque passa a sociedade, a necessidade de consumo desenfreado de informações sem sua devida 'digestão'. Nesse contexto, eleger elementos que constituam nossa memória individual e coletiva a partir de eventos narrados em rede se torna um desafio.

\section{COLETA E ANÁLISE DOS DADOS}

Como verificado na cronologia da Figura 1, o processo que desencadeou a paralisação dos caminhoneiros é anterior a maio de 2018, dadas as sequenciais negativas do Governo Federal em buscar acordo, o referido mês fora resultado da falta de diálogo entre os dois setores e palco da sucessão de notícias que tentavam clarificar os eleitores e, de certa forma, gerar comoção da opinião pública. Redes sociais como Twitter, Facebook, Instagram YouTube, 
Denise Braga Sampaio, Izabel França de Lima, Maria Nilza Barbosa Rosa, Bernardina Maria Juvenal Freire de Oliveira

Redes Sociais como Lugares Enviesados de Memória: um discurso coletivo da paralização dos caminhoneiros de 2018

principalmente foram palco da discussão do tema, por meio da postagem de seus usuários, sobretudo das páginas de notícia, caso do jornal cearense $\mathrm{O}$ Povo.

\subsection{Jornal o Povo e o Termômetro da Paralisação dos Caminhoneiros (2018)}

Os onze dias de paralisação geraram 183 postagens, com picos nos dias 25 e 28, que geraram praticamente uma postagem a cada uma hora.

\section{Gráfico 1 - Paralisação dos Caminhoneiros de 2018 - Fluxo de postagens do jornal O Povo Online no Instagram}

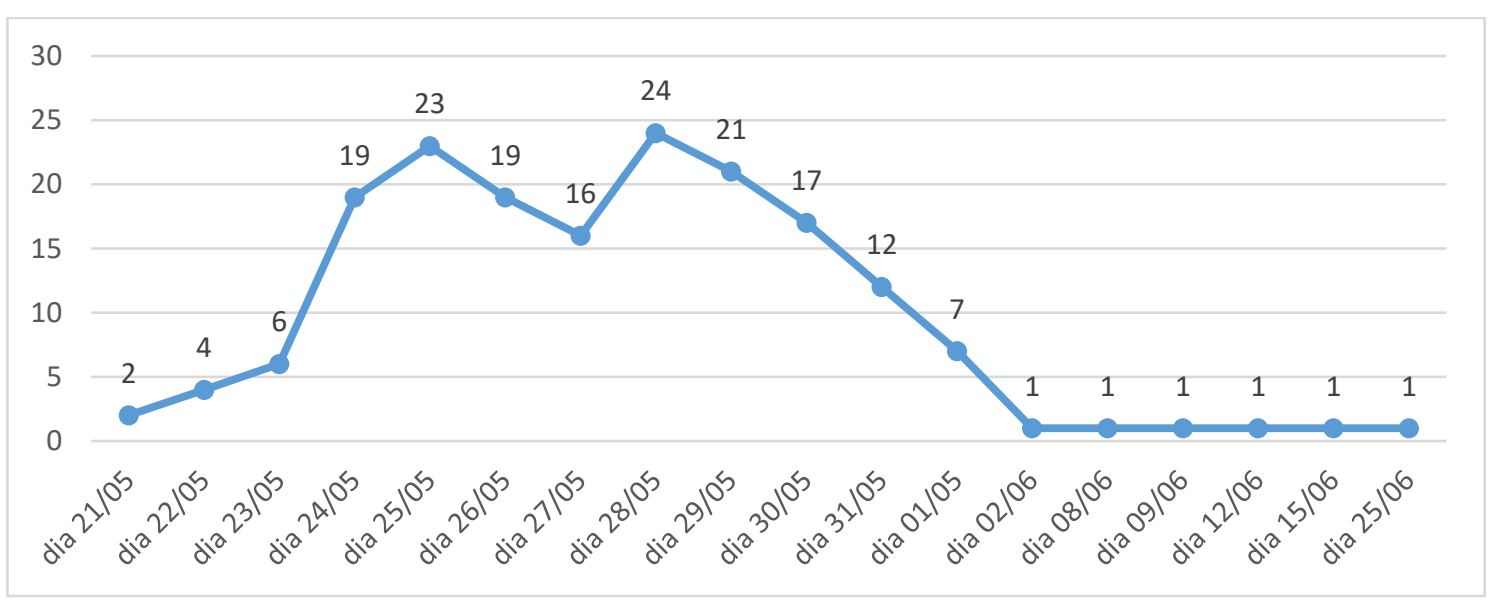

Fonte: Elaborado pelas autoras, baseada em O Povo Online

O dia 25 de maio é o dia sucessor ao atendimento parcial do Governo Federal (GF) às pautas dos caminhoneiros, o que teoricamente gera expectativa dos leitores, no entanto, tal notícia foi ofuscada pelo excesso de outras notícias, também referentes à greve. Devemos destacar que, no dia 24, o referido jornal alerta para a possibilidade de encerramento da greve graças ao acordo firmado entre caminhoneiros e GF, no entanto, os trabalhadores, no dia seguinte, 25, reafirmam o desejo de continuidade da greve. Esta postura faz o Governo autorizar o uso das Forças Armadas, inclusive para traslado de determinados insumos ${ }^{2}$. A prática adotada pelo jornal, de notícias de hora em hora, dificulta a apreciação dos acontecimentos, dado o excesso de informação ofertada no

\footnotetext{
${ }^{2}$ Verificar em: https://instagram.com/p/BjNNniqFpj1/. Acesso em: 19 jul. 2018.
} 
Denise Braga Sampaio, Izabel França de Lima, Maria Nilza Barbosa Rosa, Bernardina Maria Juvenal Freire de Oliveira

Redes Sociais como Lugares Enviesados de Memória: um discurso coletivo da paralização dos caminhoneiros de 2018

mesmo dia, para o mesmo tema. Situação similar ocorre no dia 28 , data em que a Petrobras anuncia redução de $2,8 \%$ do valor da gasolina nas refinarias ${ }^{3}$ e que o presidente da Abcam sinaliza para o término da greve ${ }^{4}$. Este é um dos pontos altos do evento, dado que mostra a desfragmentação dos grevistas e sustenta a hipótese de que o movimento poderia se tratar de um locaute. Essas notícias, apesar da importância, foram ofuscadas por outras de impacto menor, em termos de fato.

\section{Gráfico 2 - Classificação das Fotografias vinculadas às notícias no jornal O Povo Online}

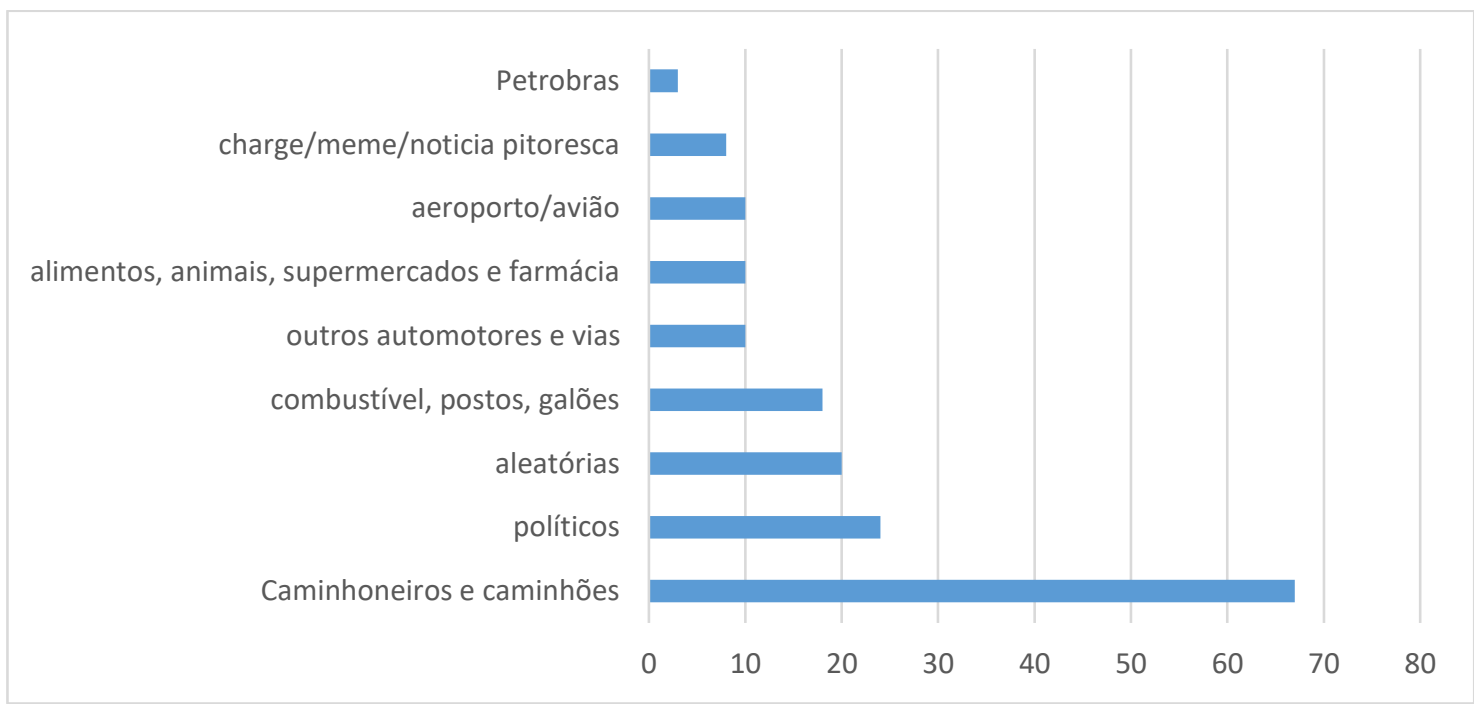

Fonte: Elaborada pelas autoras

Pode-se afirmar que os atores principais da paralisação dos caminhoneiros, além deles próprios, foram o Governo Federal e a Petrobras. $O$ GF, principalmente pela pauta de redução da taxa PIS-Cofins sobre o diesel, e a Petrobras, pela política de preços baseada na flutuação do dólar. No entanto, majoritariamente, as imagens/fotografias dos jornais, de forma muito reduzida, referiram-se à empresa, explorando mais a figura do caminhoneiro nas manifestações. Em relação aos políticos, das 24 fotos, 16 referiam-se ao presidente Temer, as demais tratavam do posicionamento dos presidenciáveis em relação à paralisação, e seis, outros políticos, como o governador do Estado

\footnotetext{
${ }^{3}$ Verificar em: https://instagram.com/p/BjUubiBFb6x/. Acesso em: 19 jul. 2018.

4 Verificar em: https://instagram.com/p/BjUqeFtF0DF/. Acesso em 19 jul. 2018.
} 
do Ceará, Camilo Santana. Nesse sentido, a precisão e a verdade visuais de que fala Le Goff, a respeito da importância da fotografia, ficam comprometidas, dado que há uma disparidade de tratamento e importância em relação aos atores que fizeram parte da paralisação. Ora, se a imagem é uma forma de instigar a memória, tão poderosa quanto a escrita, fica nítido que o tratamento desigual destes 'três personagens' compromete a percepção subconsciente dos espectadores. O que pode ser melhor percebido pela apreciação dos questionários.

No que concerne às postagens de maior repercussão, no período de 21 a 31 de maio, percebe-se que as interações dos internautas com as publicações obedecem também a picos de muitas curtidas e comentários em determinados períodos. Desta forma, as notícias de maior pico deste intervalo de dias estão conforme o Gráfico 3.

\section{Gráfico 3 - Assuntos em alta para cada dia da paralisação no 0 Povo Online}

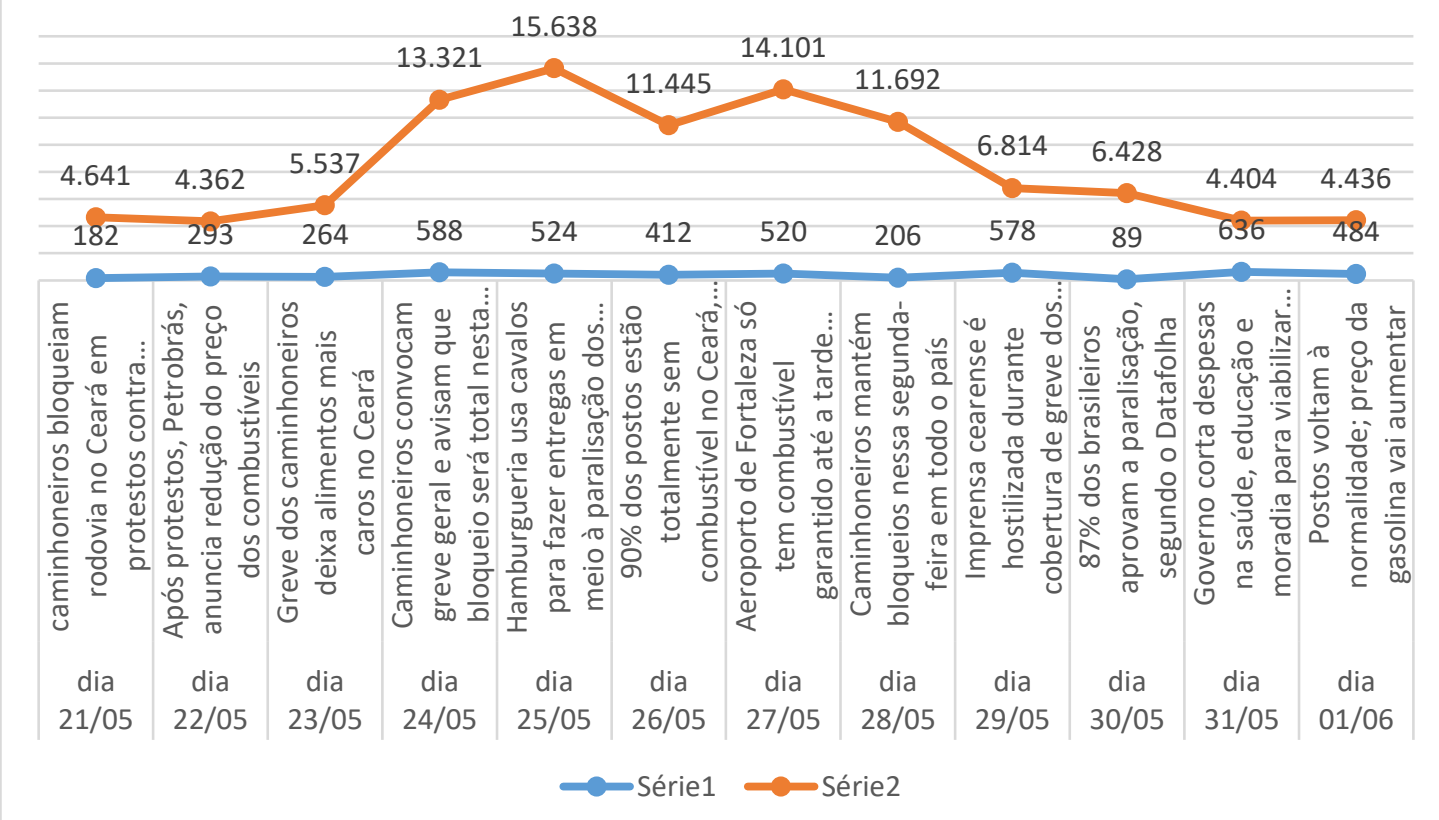

Fonte: Elaborada pelas autoras.

Em relação às curtidas (série 1 do gráfico 3), a notícia de maior interação dos internautas com o jornal O Povo foi o da hamburgueria de Planaltina (DF), que passou a fazer entregas à cavalo, para poupar gasolina. Seguida dela, a notícia da possibilidade de falta de combustível no aeroporto Pinto Martins 
(Aeroporto de Fortaleza/CE) rendeu-Ihe a segunda colocação, ficando a terceira para a continuação, no dia 28, da paralisação por parte de alguns caminhoneiros, mesmo com a recomendação da Abcam. Já os comentários (série 2 do gráfico 3) não tiveram variações tão substanciais como as curtidas. A notícia mais comentada fora a do dia 31 de maio, que anuncia cortes do Governo Federal nas áreas de saúde, educação e moradia. A comoção dos internautas foi uníssona, em discordância com a medida de enxugamento de gastos em áreas essenciais para cobrir o atendimento das pautas oriundas da paralisação. Cabe destacar que a notícia de maior repercussão do dia primeiro de junho foi justamente o anúncio de novo aumento no preço da gasolina, o que fez os leitores questionarem a justificativa dos cortes. É mister afirmar, apesar da aparente inoperância do GF, que as notícias veiculadas no jornal não são aprofundadas nas legendas das fotografias, o que cria um ambiente de maior dúvida e falta de entendimento do internauta, que geralmente é causada por desconhecimento prévio de temas como economia. O fato nos faz rememorar o entendimento de Demo (2000, p. 40), de que nossa sociedade está cada vez mais desinformada, apesar da grande quantidade de informação circulante, tanto pela fragmentação ocasionada pelas informações residuais, quanto pela hipertrofia da informação e sua oferta demasiada, o que dificulta uma apreciação mais aprofundada e de maior qualidade sobre o tema. Talvez por isso, o número de curtidas seja muito superior ao número de comentários. É um fato a se pensar.

\subsection{Usuários de Midias Sociais e sua Percepção da Paralisação doS Caminhoneiros}

Para fazer um comparativo entre o que versou o jornal O Povo e o que ficou como memória individual, fora aplicado, entre os dias 18 e 19 de julho, um questionário semiestruturado e aberto, por meio do Instagram e do WhatsApp, de forma aleatória. No total, treze pessoas responderam ao questionário. Estes, distribuídos entre Juazeiro do Norte (CE), João Pessoa (PB), Porto Velho (RO), Crato (CE), Fortaleza (CE), Recife (PE), Jaboatão dos Guararapes (PE) e Natal $(\mathrm{RN})$. A pergunta seguinte foi referente às fontes utilizadas para informar-se 
melhor a respeito da greve.

\section{Gráfico 4 - Ideias Centrais (IC) - Principais fontes consultadas pelos respondentes}

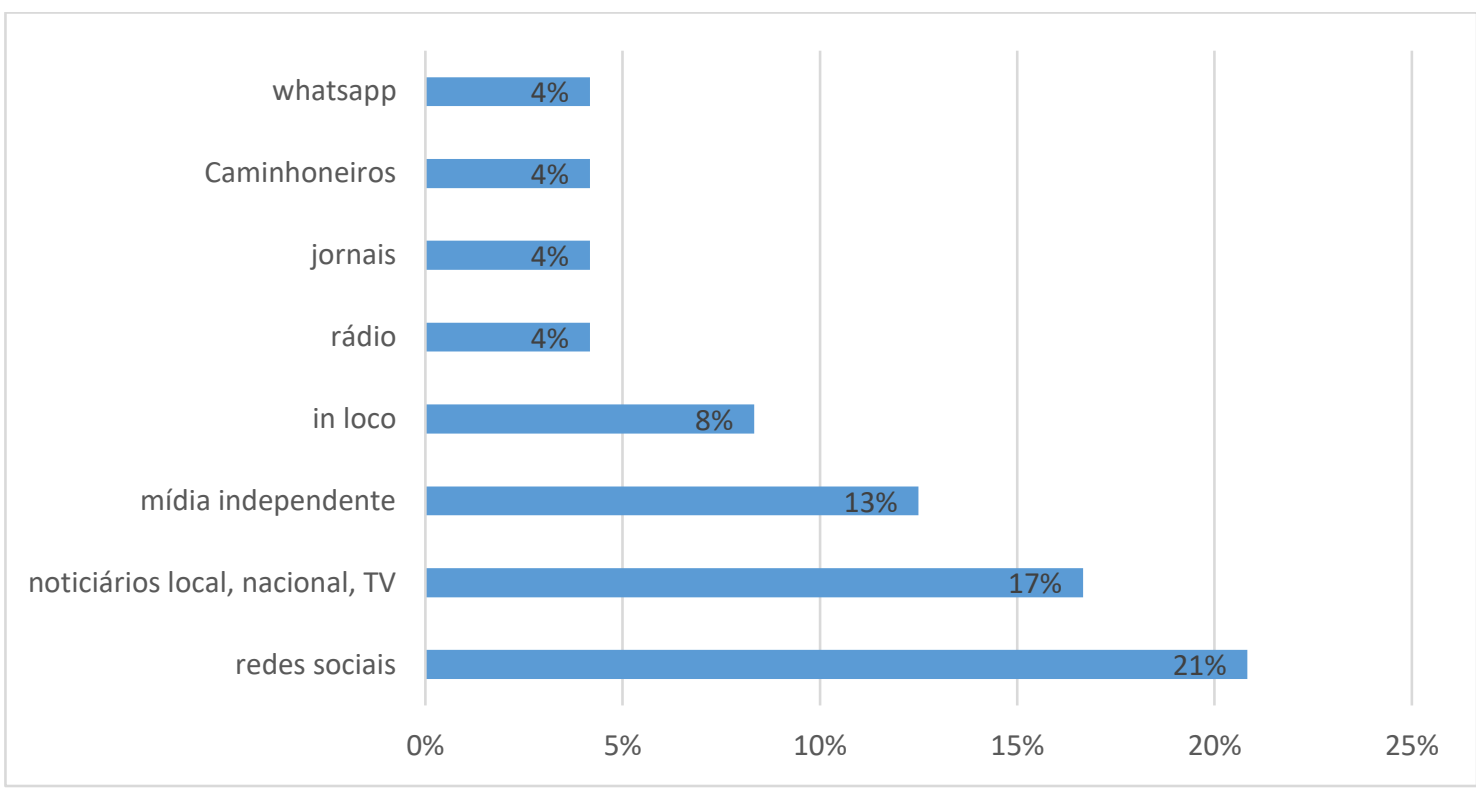

Fonte: Elaborado pelas autoras.

Foi majoritária a resposta sites/internet. Tal categoria, evidenciada pelos próprios respondentes, inclui algumas das demais fontes, como por exemplo os jornais que, atualmente, em sua maioria, circulam no meio eletrônico com maior facilidade do que no meio impresso. Um dos respondentes destacou o uso de sites tanto de cunho jornalístico como jurídico, dado o seu interesse em entender melhor a respeito do locaute. Alguns dos que citaram o uso de mídias independentes destacaram como fonte a Mídia Ninja, grupo de jornalismo ciberativista, que geralmente encontra-se em manifestações, acompanhando de perto as rotinas dos grevistas de várias categorias da classe trabalhadora. Os que buscaram informações in loco, o fizeram em percursos de viagem, nas vias federais e estaduais do país, o que os possibilitou ter maior contato com a paralisação.

Outro ponto questionado foi em relação ao uso de hashtags pelos respondentes, na paralisação. Sessenta e nove (69\%) dos respondentes não utilizaram nenhuma hashtag, enquanto $31 \%$ utilizaram \#todossomoscaminhoneiros, \#somostodoscaminhoneiros, 
\#eusoucaminhoneiros. Essas hashtags, no Instagram, tiveram adesão, respectivamente, de 728, 94.094 e 2 publicações. Esses números mostram o maior alcance e força da segunda hashtag, bem como confirma o apoio massivo da população em relação aos grevistas, dado que outras hashtags semelhantes surgiram na rede. É destacável, porém, o entendimento dos respondentes em relação à paralisação tratar-se de greve ou de locaute, lembrando que, segundo a Lei 7.783/1989 (BRASIL, 1989), o segundo configura-se em prática ilegal.

\section{Gráfico 5 - IC da Opinião dos respondentes sobre a natureza da paralisação}

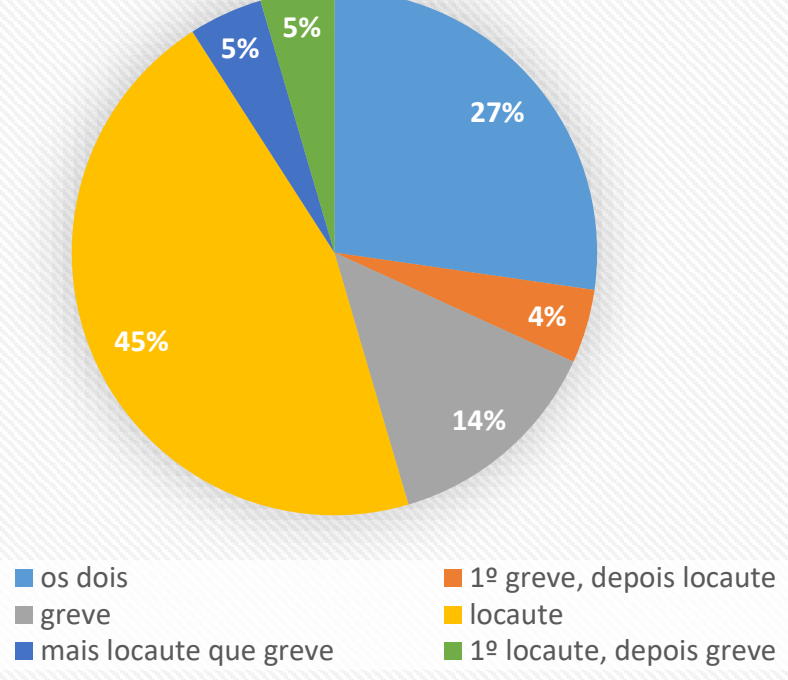

Fonte: Elaborado pelas autoras.

O entendimento de $45 \%$ dos respondentes é consoante com 0 pensamento de Ricardo Antunes (MOTA, 2018), de que a paralisação teve tanto características de greve, como de locaute, dada a confluência de interesses da classe trabalhadora com 0 patronato. No entanto, o entendimento dos respondentes não vê a relação estabelecida à época como uma confluência, mas uma tentativa do patronado em tirar proveito da mobilização, para colocar pautas de seus interesses na voz dos trabalhadores. Por fim, questionou-se a respeito das principais dificuldades encontradas no período de paralisação. As respostas foram diversas, mas giraram em torno, principalmente, da locomoção, da alimentação e do combustível. 


\section{Gráfico 6 - IC das principais dificuldades encontradas no período de paralisação}

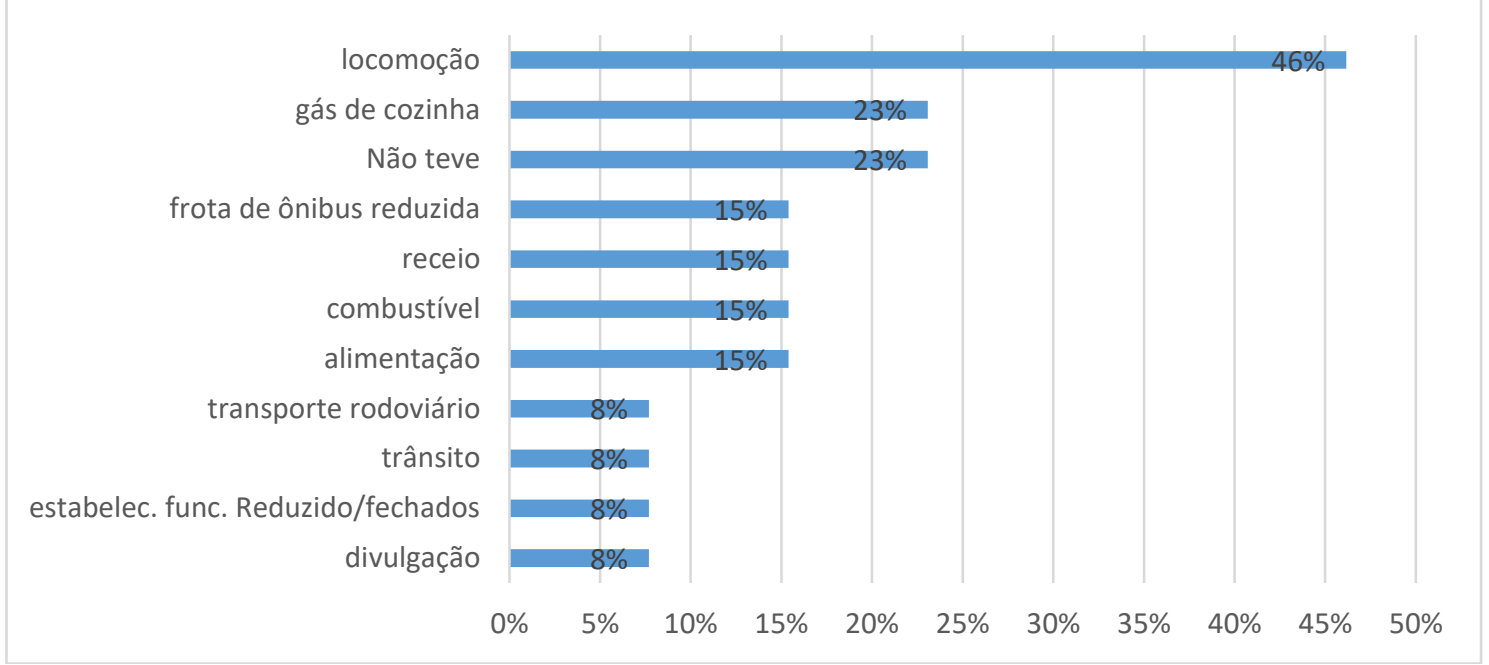

Fonte: Elaborado pelas autoras.

Alguns dos respondentes afirmaram não ter encontrado grandes dificuldades ou barreiras no período da greve, apenas receio causado pelas notícias, sobretudo nas redes sociais e nos jornais de grande circulação. Desta forma, o DSC resultante foi:

A paralisação dos caminhoneiros foi tanto locaute, como greve. As principais fontes que busquei para obter mais informações a respeito foram a internet, as redes sociais e veículos de comunicação tanto alternativos, como tradicionais. As principais dificuldades que senti no período foram a locomoção, principalmente para quem depende de transporte público, a falta de alguns alimentos nos supermercados, mas nada que não possa ser substituído por outros gêneros alimentícios da região em que moro. A falta de gás de cozinha e seu encarecimento também me foram objeto de preocupação. E, realmente, não costumo usar muitas hashtags em minhas buscas. No mais, creio que a paralisação em muito pouco ajudou aos caminhoneiros e a população em geral, afinal, nada mudou de lá para cá. (Própria autoria, com base nos dados coletados).

O DSC é contemplado pelas principais notícias em alta no jornal O Povo, o que mostra tangência entre a memória individual dos participantes e o que fora sentido na coletividade, à época da paralisação. Ao verificar-se o Gráfico 3, um dos únicos pontos não destacados foi a falta de alimentos. Apesar de não ter sido destaque, foi matéria ao longo dos dias em que transcorreu a paralisação. Outro fator importante foi a divulgação do desfecho da greve (Gráfico 3), tratado no dia 01 de junho de 2018, revelando que, passados os onze dias de 
paralisação, um novo aumento de combustíveis iria ocorrer. Certamente por esse desfecho, a sensação de inoperância da greve tenha sido sentida pelos respondentes. Segundo afirma Magalhães (2004, p. 197), na memória reside a importância para a promoção de "diferentes projetos políticos e conquista de direitos" que coaduna passado, presente e futuro por meio de narrativas e imagens. Essas, como se percebe, são depositárias dos fatos sob a ótica de quem os vê e revela.

\section{CONSIDERAÇÕES FINAIS}

É notório, a partir do desvelado na discussão, que as narrativas dos veículos de informação e comunicação atuais, tradicionais, ou alternativos, tornam-se parte constituinte de nossas memórias, direta ou indiretamente. Mesmo aqueles que não passaram por dificuldade no que diz respeito à busca de gêneros alimentícios, por exemplo, sentiram-se temerosos pela possibilidade de falta de algum produto essencial em casa.

As redes sociais tomaram-se parte significativa do processo de aquisição de informações para pessoas que vivem em rede, somando $38 \%$ dos respondentes na pesquisa (entre os que afirmaram usar redes sociais, WhatsApp e mídia alternativa), o que corrobora com o entendimento de autores como Gasque (2016); Ferreira; Luz; Maciel (2015), fazendo-nos inferir que, a partir dessa obtenção de informações nascem memórias passíveis de acesso sempre que um écran é aberto, ou uma discussão se inicia. Nesse sentido, alguns documentos imagéticos tornam-se emblemáticos em relação a determinado fato, como foi o caso de vídeos de caminhoneiros que viralizaram nas redes sociais, uns chorando, outros indignados por suas condições de trabalho. Tal recurso mexe com os sentimentos das pessoas, deixando marcas em quem viveu o fato narrado, seja de forma direta, seja mediada. Aproximar pessoas por meio dessas redes, que se formam nos intercâmbios de vídeos, imagens e textos é um caminho de rememoração, da prática do velar e desvelar de fatos a partir de sentimentos gerados pela percepção dos olhos e ouvidos.

No entanto, essas memórias podem, devido ao sentimento que se 
deposita sobre elas, esconder narrativas falhas, incertas e pautadas em enviesamentos arbitrados pelos jogos de poder que concorrem para uma memória coletiva, social, uníssona e atendente a interesses que não deste coletivo. O jornal O Povo, por exemplo, publicara apenas uma matéria a respeito de um possível locaute na paralisação, em meio a um grande fluxo de postagens de outras naturezas, o que dificultou o entendimento e processamento desta informação para maior apreciação dos fatos. Concorre a esse entendimento o fato de alguns dos respondentes terem pedido maiores explicações a respeito do que se trata essa prática. Portanto, a cautela nas redes sociais é fator preponderante para obtenção de informações, mais ainda para a formação de memórias individuais e coletivas.

\section{REFERÊNCIAS}

ARENDT, H. Entre o passado e o futuro. 8. ed. São Paulo: Perspectiva, 2016. BAUMAN, Z. Modernidade líquida. Rio de Janeiro: Zahar, 2011.

BELO, F. Leitura da introdução sobre a verdade e a mentira em Nietzsche. In: BELO, F. Leituras de Aristóteles e de Nietzsche: a poética sobre a verdade e a mentira. Lisboa: Fundação Calouste Gulbenkian, 1994. p. 206-263.

BORGES, R. Greve dos caminhoneiros: como se formou o nó que levou à paralisação. El País, São Paulo, 26 maio 2018. Economia, Crise dos combustíveis no Brasil. Disponível em:

https://brasil.elpais.com/brasil/2018/05/24/economia/1527177800_693499.html. Acesso em: 12 jul. 2018.

BOSI, A. Considerações sobre o tempo e a informação. In: SEMINÁRIO INTERNET, MENTE E SOCIEDADE, São Paulo, 1995. Anais [...]. São Paulo: IEA, 1995. Disponível em: http://www.iea.usp.br/publicacoes/textos/bosiinternet.pdf. Acesso em: 15 jul. 2018.

BRASIL. Câmara dos Deputados. Projeto de Lei n. 528, de março de 2015.Cria a política de preços mínimos do Transporte Rodoviário de Cargas. Brasília:

Câmara dos Deputados, 5 mar. 2015. Disponível em:

https://www.camara.leg.br/proposicoesWeb/fichadetramitacao?idProposicao=9 55516. Acesso em: 12 jul. 2018. 
BRASIL. Lei no 7.783 , de 28 de junho de 1989. Dispõe sobre o exercício do direito de greve, define as atividades essenciais, regula o atendimento das necessidades inadiáveis da comunidade, e dá outras providências. Brasília: Diário Oficial União, 28 jul. 1989. Disponível em: http://www.planalto.gov.br/ccivil_03/Leis/L7783.htm. Acesso em: 12 jul. 2018.

BRASIL. Lei n. 12.619, de 30 de abril de 2012. Dispõe sobre o exercício da profissão de motorista; altera a Consolidação das Leis do Trabalho [...]. Brasília: Diário Oficial União, 30 abr. 2012. Disponível em: http://www.planalto.gov.br/ccivil_03/_Ato2011-2014/2012/Lei/L12619.htm. Acesso em: 12 jul. 2018.

BRASIL. Lei n. 13.103, de 2 de março de 2015. Dispõe sobre o exercício da profissão de motorista; altera a Consolidação das Leis do Trabalho [...]. Brasília: Diário Oficial União, 2 mar. 2012. Disponível em: http://www.planalto.gov.br/ccivil_03/_ato2015-2018/2015/lei//13103.htm. Acesso em: 12 jul. 2018.

DEMO, P. Ambivalência da Sociedade da Informação. Ci. Inf., Brasília, v. 29, n. 2, p. 37-42, maio/ago., 2000. Disponível em http://revista.ibict.br/ciinf/article/view/885. Acesso em: 16 jul. 2018.

ENTENDA a curta história do Instagram, comprado pelo Facebook. G1, São Paulo, 16 abr. 2012. Tecnologia e Games. Disponível em: http://g1.globo.com/tecnologia/noticia/2012/04/entenda-curta-historia-doinstagram-comprado-pelo-facebook.html. Acesso em: 14 jul. 2018.

FERREIRA, P. A.; LUZ, C. R. M. da; MACIEL, I. M. S. As redes sociais como fonte de informação: uso do Whatsapp como ferramenta de apuração de notícias. In: CONGRESSO BRASILEIRO DE CIÊNCIA DA COMUNICAÇÃO, 38., 2015, Rio de Janeiro. Anais [...]. Rio de Janeiro: INTERCOM, 2015. Disponível em: http://portalintercom.org.br/anais/nacional2015/resumos/R103508-1.pdf. Acesso em: 11 jul. 2018.

FONTCUBERTA, J. A câmera de Pandora, A fografi@ depois da fotografía. São Paulo: Editora G. Gilli, 2012.

GASQUE, K. C. G. D. Internet, mídias sociais e as unidades de informação: foco no ensino-aprendizado. Brazilian Journal of Information Studies: Research Trends, v. 10, n. 2, p. 14-20, 2016. Disponível em: https://www.google.com/url?sa=t\&rct=j\&q=\&esrc=s\&source=web\&cd=11\&cad=rj a\&uact $=8 \&$ ved=0ahUKEwjGjJba15fcAhVJ2IMKHRZcCn04ChAWCCgwAA\&url= https\%3A\%2F\%2Fdialnet.unirioja.es\%2Fdescarga\%2Farticulo\%2F5645863.pdf \&usg=AOvVaw3yqXH8hvVmyN7xJ4XZD4Dh. Acesso em: 11 jul. 2018.

GREVE de caminhoneiros ou locaute de empresas. Pragmatismo Político, 24 maio 2018. Governo. Disponível em: 
https://www.pragmatismopolitico.com.br/2018/05/locaute-ou-greve-decaminhoneiros.html. Acesso em: 13 jul. 2018.

"GREVEDOSCAMINHONEIROS" chega aos Trending Topics do Twitter com apoio às manifestações. Diário do Centro do Mundo, 24 maio 2018. O essencial. Disponível em:

https://www.diariodocentrodomundo.com.br/essencial/grevedoscaminhoneiroschega-aos-trending-topics-do-twitter-com-apoio-as-manifestacoes/. Acesso em 14 jul. 2018.

GREVE dos caminhoneiros rende 8,8 milhões de posts em redes sociais. Notícias ao minuto, 31 maio 2018. Tech ao minuto, Repercussão. Disponível em: https://www.noticiasaominuto.com.br/tech/600923/greve-doscaminhoneiros-rende-8-8-milhoes-de-posts-em-redes-sociais. Acesso em: 14 jul. 2018.

HALBWACHS, M. A Memória coletiva. São Paulo: Vértice/Revista dos Tribunais, 1990.

HOBSBAWN, E. J. A era das revoluções. Rio de Janeiro: Paz e Terra, 1977.

KESSEL, Z. Memória e memória coletiva. São Paulo: Museu da Pessoa, 2003 (Conteúdo para Portal).

LEFEVRE, F; LEFEVRE, A. M. C. Discurso do Sujeito Coletivo: representações sociais e intervenções comunicativas. Texto Contexto Enferm., Florianópolis, v. 23, n. 2, p. 502-507, abr./jun. 2014. Disponível em:

http://www.scielo.br/pdf/tce/v23n2/pt_0104-0707-tce-23-02-00502.pdf. Acesso em: 17 jul. 2018.

LEFEVRE, F.; LEFEVRE, A. M. C. O discurso do sujeito coletivo: um novo enfoque em pesquisa qualitativa. Porto Alegre: Educs, 2003. 255 p. (Coleção Diálogos).

LE GOFF, J. História e memória. Campinas: Editora Unicamp, 1990.

LUZ, A. L. L..; WOITOWICZ, K. J. Jornalismo nas Redes Sociais: Instagram e Facebook como Plataformas para Produção de Conteúdo Multimídia pelo Sítio Cultura Plural. In: CONGRESSO BRASILEIRO DE CIÊNCIAS DA COMUNICAÇÃO, 40., 2017, Curitiba. Anais [...]. Curitiba: INTERCOM, 2017. Disponível em: http://portalintercom.org.br/anais/nacional2017/resumos/R122289-1.pdf. Acesso em 14 jul. 2018.

MAGALHÃES, N. A. Memória, imagem e raízes da vida. Textos de História: Brasília, v. 12, n. 1-2, 2004. Disponível em: https://periodicos.unb.br/index.php/textos/article/view/27869. Acesso em 19 jul. 2018. 
MANOLO. Caminhoneiros: o que ficou de fora da pauta. Passa palavra, 30 maio 2018. Noticiar, Brasil. Disponível em:

http://passapalavra.info/2018/05/119973. Acesso em 13 jul. 2018.

MARX, K. O capital: Crítica da Economia Política. [S.I.]: Boitempo, 1867. (Livro 1: o processo de produção do capital). (edição eletrônica). Disponível em: https://www.marxists.org/portugues/marx/1867/capital/index.htm. Acesso em: 15 jul. 2018.

MOTA, C. V. Paralisação de caminhoneiros é um misto de greve e de locaute, diz sociólogo do trabalho. BBC Brasil, São Paulo, 25 maio 2018. Disponível em: https://www.bbc.com/portuguese/brasil-44256413. Acesso em 14 jul. 2018.

MOTTA, L. F. Veja quem são os caminhoneiros, o que eles pedem e quem passa pelos bloqueios. O tempo, Belo Horizonte, MG, 24 maio 2018. Cidades, Entenda. Disponível em: https://www.otempo.com.br/cidades/veja-quems\%C3\%A3o-os-caminhoneiros-o-que-eles-pedem-e-quem-passa-pelosbloqueios-1.1835849. Acesso em: 13 jul. 2018.

MOURA, R. A cronologia da crise do diesel, do controle de preços de Dilma à greve dos caminhoneiros. BBC Brasil, Londres, UK, 24 maio 2018. Disponível em: https://www.bbc.com/portuguese/brasil-44239437. Acesso em: 12 jul. 2018.

PIZA, M. V. O fenômeno Instagram: considerações sob a perspectiva tecnológica. 2012. 48 f. Monografia (Bacharelado em Ciências Sociais com habilitação em Sociologia) - Departamento de Sociologia, Universidade de Brasília, Brasília, 2012. Disponível em: http://bdm.unb.br/bitstream/10483/3243/1/2012_MarianaVassalloPiza.pdf. Acesso em: 11 jul. 2018.

PORTINARI, N. Entenda o movimento dos caminhoneiros, que faz $5^{\circ}$ dia de paralisação. Folha de São Paulo, São Paulo, 25 maio 2018. Mercado. Disponível em: https://www1.folha.uol.com.br/mercado/2018/05/entenda-aparalisacao-dos-caminhoneiros-que-chega-ao-5o-dia.shtml. Acesso em: 12 jul. 2018.

\title{
SOCIAL NETWORKS AS BIASED PLACES OF MEMORY: THE DISCOURSE OF THE COLLECTIVE SUBJECT ABOUT STRIKE BY TRUCK DRIVERS IN BRAZIL
}

\begin{abstract}
It is an exploratory research whose main objective is to uncover the relations between collective memory and social networks, especially Instagram. The goals are to verify the photos related to the truck stoppage (occurred in May 2018) in Instagram of the
\end{abstract}


newspaper O Povo Online, categorize these publications according to criteria of form and content and verify the main ideas stated in the captions of photographs of the most tanned posts by the readers. For such an assessment, it uses the semistructured questionnaire and O Povo Online's news about the truckers' strike. The data collected in the questionnaire were weighted by the discourse of the Collective Subject and compared with the publications of the newspaper, resulting in that social networks are a potential remembrance tool, however, limited thanks to its dynamic and fluid nature.

Descriptors: Collective memory. Social Networks. Strikes. Road transport.

\title{
LAS REDES COMO LUGARES DE LA MEMORIA SESGADOS: UN DISCURSO DEL SUJETO COLECTIVO DE LA PARALISIÓN DE LOS CAMINOS DE 2018
}

\begin{abstract}
RESUMEN
Se trata de investigación exploratoria cuyo objetivo principal es el de descortinar las relaciones existentes entre memoria colectiva y redes sociales, en especial, el Instagram. Los objetivos específicos son verificar las fotografías relacionadas con la paralización de los camioneros (ocurrida en mayo de 2018) en el Instagram del diario cearense $O$ Povo Online, categorizar esas publicaciones según criterios de forma y contenido y verificar las ideas principales enunciadas en las leyendas de las fotografías de los postes más curtidos por los lectores. Para tal apreciación, toma por instrumentos de la investigación el cuestionario semiestructurado y las materias del O Povo Online referentes a la paralización. Los datos recogidos en el cuestionario fueron sopesados por el Discurso del Sujeto Colectivo y comparados con las publicaciones del periódico, dando por resultado que las redes sociales son una potencial herramienta de rememoración, sin embargo, limitadas gracias a su naturaleza dinámica y fluida.
\end{abstract}

Descriptores: Memoria Colectiva. Redes sociales. Greve. Transporte por carretera.

Recebido em: 27/09/2019

Aceito em: 09/02/2020 